\title{
Rosimar Abreu Leal
}

\section{Política de Atendimento ao Adolescente em Cumprimento de Medidas Socioeducativas em Meio Aberto na Cidade de Nova Iguaçu}

Dissertação de Mestrado

Dissertação apresentada como requisito parcial para obtenção do título de Mestre pelo Programa de Pós-Graduação em Serviço Social da PUC-Rio.

Orientadora: Profa. Ilda Lopes Rodrigues da Silva 
Política de Atendimento ao Adolescente em Cumprimento de Medidas Socioeducativas em Meio Aberto na Cidade de Nova Iguaçu

Dissertação apresentada como requisito parcial para obtenção do título de Mestre pelo Programa de Pós-Graduação em Serviço Social da PUC-Rio. Aprovada pela Comissão Examinadora abaixo assinada.

Profa. Ilda Lopes Rodrigues da Silva Orientadora Departamento de Serviço Social da PUC-Rio

Prof. Antonio Carlos de Oliveira Departamento de Serviço Social - PUC-Rio

Profa. Celeste Anunciata Baptista Dias Moreira UNIRIO

Profa. Mônica Herz Coordenadora Setorial do Centro de Ciências Sociais - PUC-Rio 
Todos os direitos reservados. É proibida a reprodução total ou parcial do trabalho sem autorização da universidade, da autora e do orientador.

\section{Rosimar Abreu Leal}

Graduou-se em Serviço Social pela Pontifícia Universidade Católica do Rio de Janeiro. Pósgraduada em Marketing pela Universidade Estácio de Sá. Atuou na área da Política de Assistência Social no Estado do Rio de Janeiro e Cidade de Nova Iguaçu. Áreas de interesse: Políticas Sociais, Gestão Pública e SócioJurídica.

Ficha Catalográfica

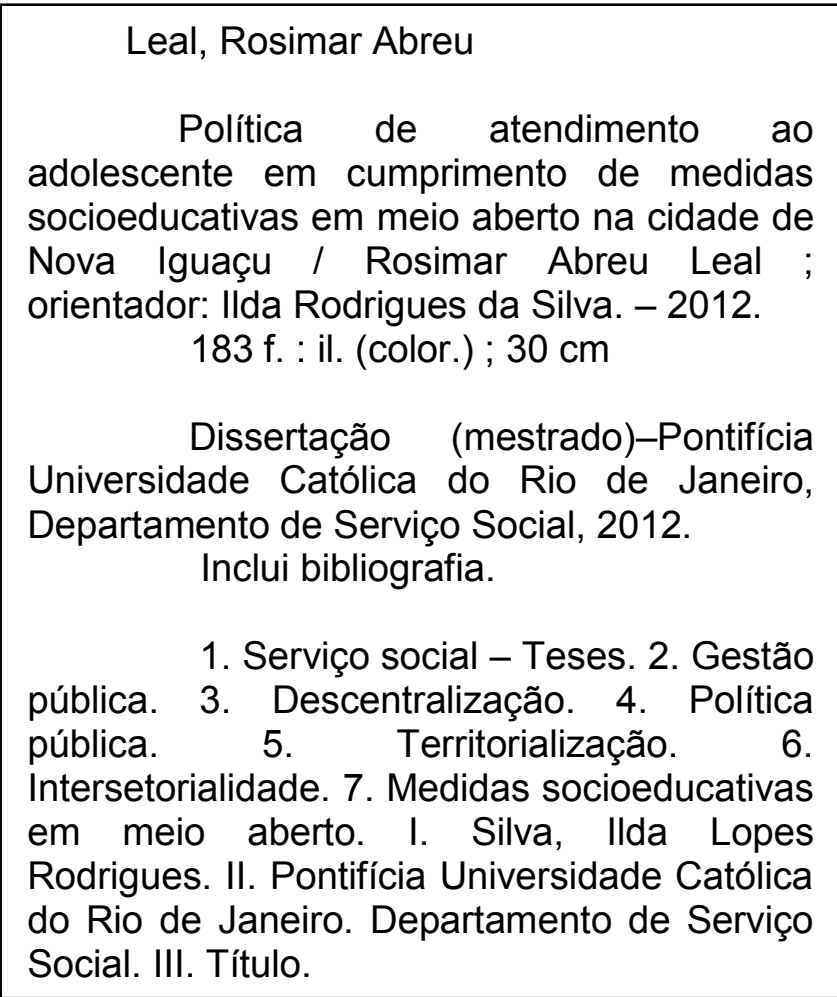


A minha mãe Josépha, Pela dedicação, presença e pelo companheirismo. $\mathrm{O}$ que seria da minha vida sem você? A tua sabedoria, até hoje, aos 87 anos de vida, fortalece a minha caminhada.

A meu pai Assis de Carvalho (in memoriam), Meu eterno exemplo de vida.

Ao meu companheiro, amigo, esposo José Aureo.

Aos nossos filhos, Igor e Beatriz,

Agora, se sonho se resisto são por vocês. Agradeço pela existência de vocês em minha vida e por terem ficado ao meu ao meu lado nesta caminhada. 


\section{Agradecimentos}

A Deus que sabe de todas as coisas e é onipresente em minha vida.

À PUC-RIO e a CAPES pela concessão de bolsas de estudos que possibilitaram concretizar este trabalho acadêmico.

À toda equipe do Departamento de Serviço Social, desde o corpo docente ao corpo administrativo por terem creditado confiança e oportunizado a estrutura necessária para realização da pesquisa.

Aos docentes da PUC-Rio, por partilharem conhecimento que contribuíram para além da formação técnico-operacional, presente e mutante, aprender a ser.

Aos amigos de "longa data" que torcem por minhas vitórias: Lianzi dos Santos Silva, Denise Lima, Sonia Lim, Ronaldo Júlio, Renato Eller, Izabel Cristina e Porcina. Alguns recentes, mas se tornaram fundamentais na idealização desse projeto: Lucília Carvalho, Jocelene Ignácio e Mônica Ferrarez.

Aos amigos da SEASDH- Secretaria Estadual de Assistência Social e Direitos Humanos, especialmente a equipe da Proteção Especial, na qual tive a honra de fazer parte e reconheço a sua devida importância no processo desta conquista: 
Heloísa Mesquita, Tânia Brasil, Ana Paula, Claudia Mello, Natália, Maria do Socorro, Nancy, Marcella, Diana, Paula e Amália.

Ao professor Antônio Carlos e a professora Celeste Anunciata que participaram da Banca Examinadora de forma respeitosa, realizando leitura e revisão crítica do trabalho.

A minha orientadora Ilda Lopes que de forma ética, competente conduziu a produção desse trabalho.

Aos colegas do curso pela grande interação, debates e trocas que enriqueceram a inserção no campo de pesquisa.

À SEMASPV - Secretaria Municipal de Assistência Social e de Prevenção a Violência, em especial, Secretário, Observatório da Violência e a equipe do CREAS que, prontamente, se disponibilizaram em participar da pesquisa.

Aos familiares que apoiaram e entenderam, muitas vezes, minha ausência. E sem dúvidas, presentes em momentos imprescindíveis deste processo, em especial, a Vovó Penha e Vovó Zefa - que protegeram e cuidaram dos meus rebentos em minha ausência. 


\section{Resumo}

Leal, Rosimar Abreu; Silva, Ilda Rodrigues (orientador). Política de Atendimento ao Adolescente em Cumprimento de Medidas Socioeducativas em Meio Aberto na Cidade de Nova Iguaçu. Rio de Janeiro, 2012. 183 p. Dissertação de Mestrado - Departamento em Serviço Social, Pontifícia Universidade Católica do Rio de Janeiro.

O presente trabalho objetiva analisar o processo de municipalização da política de atendimento ao adolescente em cumprimento de medida socioeducativa em meio aberto na Cidade de Nova Iguaçu. A fundamentação do estudo parte do resgate dos diferentes modelos de gestões de políticas públicas constituídas ao longo da história brasileira sob influência das mudanças capitalistas. Assim, analisa alguns períodos históricos da administração púbica brasileira que perpassa pelas diversas mudanças nas formas de gestão da política pública, a descentralização das políticas públicas sociais brasileiras no marco dos anos 80. E como também, caracteriza a tentativa de reforma do estado, a configuração das políticas sociais nos anos 90 e a forma da condução do trabalho social através das ações socioeducativas. O processo de análise teve como referências as categorias gestão pública, intersetorialidade, territorialização que têm papel primordial na implementação da política de atendimento ao adolescente no município. Este por sua vez requer um reordenamento institucional para municipalização da politica, tanto no aspecto legal quanto nos aspectos de infraestrutura, recursos humanos, destinação orçamentária, integração com comunidade e inclusão na agenda política do município. Diante desta nova realidade exige-se que o município tenha uma gestão pública inteirada das reais demandas locais, como integrada com a rede local, com o sistema de garantia de direitos na concretização da implementação e da política de atendimento ao adolescente em cumprimento de medida socioeducativa em meio aberto.

\section{Palavras-chave}

Gestão Pública; Descentralização; Política Pública; Territorialização; Intersetorialidade; Medidas Socioeducativas em Meio Aberto. 


\begin{abstract}
Leal, Rosimar Abreu; Silva, Ilda Rodriguez (Advisor). Policy on Adolescent Care Compliance Measures Socioeducational Mid City Open in Nova Iguaçu. Rio de Janeiro, 2012. 183p. MSc. Dissertation Departamento de Serviço Social da Pontifícia Universidade Católica do Rio de Janeiro.
\end{abstract}

This study aims to analyze the process of decentralization of health care to adolescents in under socio amid open in the city of Nova Iguaçu. The rationale of the study part of the rescue efforts of different models of public policy established throughout Brazilian history under the influence of changes capitalists. Thus, examines some of the historical periods that pervades Brazilian pubic administration by the various changes in the way public policy management, decentralization of social policies in Brazil March 80. And it also characterizes the attempt to reform the state, the configuration of social policies in the 90 s and the way of conducting social work through social and educational activities. The analysis process was to references the categories governance, intersectoral, territorialization that have key role in the implementation of health care to adolescents in the county. This in turn requires a reordering of institutional decentralization policy in both the legal aspect as in aspects of infrastructure, human resources, budgetary allocation, community integration and inclusion in the political agenda of the municipality. Faced with this new reality requires that the municipality has a public management inteirada of real local demands, as integrated with the network, with the guarantee of rights and the achievement of the implementation of health care to adolescents in under socio-in an open environment.

\title{
Keywords
}

Public Management; Decentralization, Public Policy; Territorialization; Intersectoriality; Socioeducational Measures in Half Open. 


\section{Sumário}

1 Introdução

2 A Gestão das Políticas Públicas Brasileiras 21

2.1. Anos 80: mudanças na forma de gerir a coisa pública 21

2.2. A tentativa de reforma do Estado 26

2.3. As políticas sociais brasileiras nos anos $90 \quad 37$

2.4. Trabalho socioeducativo na política de assistência social 45

3. Descentralização das Políticas Públicas sociais brasileiras 50

3.1. Descentralização a partir dos anos 80

3.2. Políticas Públicas e Territorialização 53

3.3. Ação intersetorial: perspectiva de integração das políticas públicas

60

4 A constituição da Política de Atendimento ao Adolescente em Conflito com a Lei no marco dos anos 80

4.1. Diretrizes internacionais de proteção ao adolescente em conflito com a lei

4.2. Deliberações do CONANDA em matéria do adolescente em conflito com Lei

4.3. O SINASE - Projeto de Lei de execução das medidas socioeducativas

4.3.1. A Lei do SINASE: avanços e conquistas

5 A Cidade de Nova Iguaçu e os indicadores sociais 98

5.1. Características gerais 98

5.2. Dados, programas e projetos sociais 110

6 Caracterização da política de atendimento ao adolescente em meio aberto em Nova Iguaçu 
6.1. Gestão da Política Pública 124

6.2. Intersetorialidade 143

6.3. Territorialização 151

7 Considerações finais 163

8 Bibliografia 169

$\begin{array}{ll}\text { Anexos } & 180\end{array}$ 